\title{
Caminhos e descaminhos nas Ciências do Desporto. Entre o Porto Alegre e o Porto Sentido.
}

\author{
Adroaldo Gaya \\ Escola de Educação Física, \\ Universidade Federal do Rio Grande do Sul \\ https://doi.org/10.5628/rpcd.01.01.80
}

\section{APRESENTAÇÃO}

O presente ensaio trata de dois aspectos principais: (a) refazer alguns caminhos referentes as reflexões sobre a epistemologia das ciências do desporto e (b) sugerir que a Faculdade de Ciências do Desporto e de Educação Física da Universidade do Porto (FCDEFUP) em ações com importantes Universidades brasileiras e com a Universidade Pedagógica de Moçambique em Maputo, a partir do amplo espectro de publicações, cursos, mobilidade de professores e estudantes, em programas de mestrado e doutoramento, tem proporcionado conteúdo teórico e empírico capaz de permitir a configuração de um pensamento consistente sobre os vários aspectos do desporto no espaço da língua portuguesa.

Vou tratar destes objetivos, mas não sem antes propor uma reflexão passível de evidenciar o quanto é limitada nossa capacidade de percepção e nossas possibilidades de conhecimento sobre os fenômenos complexos que nos cercam no cotidiano de nossas vidas. Pretendo sugerir num breve texto introdutório a dificuldade que encontramos sempre que temos a pretensão de apreender fenômenos complexos. Por exemplo, como apreender o desporto em sua multiplicidade de formas e sentidos? Qual o papel que assume o discurso científico ou filosófico nesta proposição? Terá sentido a pretensão de delimitar a(s) ciência(s) do desporto? Terá o conhecimento filosófico a capacidade de assumir tal responsabilidade? Mas, por outro lado, poderemos prescindir dessas formas de conhecimento para entendermos o significado do desporto? Enfim, como devemos teorizar sobre o desporto?

\section{EM FORMA DE INTRODUÇÃO. UMA IMAGEM SOBRE OS LIMITES DA PERCEPÇÃO E DO CONHECIMENTO HUMANO}

Estou frente a uma imensa janela. Daí observo a imagem de um bosque ao fim do Outono.

O bosque está iluminado pelos raios do sol poente. As poucas folhagens, característica desta estação do ano, fazem os raios do sol incidirem sem piedade sobre a vidraça que, não obstante, gentilmente me resguarda do frio que se faz sentir do lado de fora. A luz do sol sobre as árvores desfolhadas revelam um mapa estranho de sombras e luz. Mas, é possível ver ao longe, e com algum esforço de concentração, detalhes de crianças que jogam bola e divertem-se num campo improvisado por entre os galhos e troncos semi-nús do arvoredo.

Às minhas costas, "nós de pinho" e "achas de lenhas de araucária" ardem numa lareira de pedras. O fogo me aquece, aquece o ambiente, eu me sinto bem. Me volto para a lareira e percebo o bailado anárquico das labaredas que se erguem em direção ao céu acompanhadas do criptar e do perfume acre da lenha seca. É um belo espetáculo.

Ponho-me a contemplar a beleza do ballet das labaredas e das sombras refletidas sobre o fundo da lareira.

Agora estou dividido na curiosidade. Acompanhar o ballet? Ou desfrutar do jogo de bola das crianças no bosque?

Imediatamente dou-me conta das limitações de nossa estrutura biológica. Não poderei desfrutar das duas paisagens ao mesmo tempo. Se me dedicar ao jogo de bola, evidentemente não vou desfrutar do ballet na lareira feita palco e vice-versa. Todavia, e este é um ponto relevante para os 
argumentos que adiante quero defender, é indiscutível, pelo menos no que tange a filosofia que partilho, que ao optar pelo jogo de bola, a realidade para a qual eu darei as costas não deixa de existir. Mas, é bem verdade, aqui já estamos propondo ler o mundo através de uma determinada perspectiva filosófica. Qual seja: o simples fato de que ao deixar de acompanhar o movimento das labaredas, tenho presente de que elas não deixam de existir. Ou seja, reconheço o princípio de uma essência do conhecimento onde há um mundo concreto para além de minha capacidade de percebê-lo. Afinal, não posso dar conta de todos os fenômenos. Se ao dormir não percebo a chuva da madrugada, nem por isso ela deixou de molhar a terra.

Me volto de frente para a janela. Por entre as árvores do bosque acompanho o jogo de bola das crianças. Então revivo parte de meu caminho acadêmico. Do Porto Alegre ao Porto Sentido. Que pretensão desmedida seria esta de imaginar que teria a possibilidade de apreender os significados do desporto através do discurso científico - a(s) ciência(s) do desporto?

Observo lá, no campo improvisado entre as árvores e exclamo com ironia: lá estão as crianças desfrutando irresponsavelmente de meu objeto de estudo! Ou, quem sabe, estão seriamente desfrutando de seu objeto de prazer? Qual o real? Qual o ideal? O jogos de bola em seu amplo significado? Ou será o discurso sobre o jogo de bola? Discurso sempre incompleto, idealizado, sempre pintado com as cores de nosso espírito, ideologizado segundo nossas crenças. Será possível apreender a complexidade do desporto no âmbito do discurso científico? Será possível apreender a complexidade do desporto no espaço do discurso filosófico?

Deixo claro. Não tenho a pretensão de julgar improcedentes ou desnecessários os estudos que se dedicam a tentativa de configurar o conhecimento científico ou filosófico sobre o desporto. Não se trata de assumir posições de ceticismo. Afinal, somos professores e pesquisadores universitários e devemos tratar o desporto como objeto de nossa reflexão teórica. Necessitamos interpretar os diversos significados do desporto. Todavia, estou convencido, jamais esta tarefa poderá ser concluída, e muito menos por um único sujeito. Por mais genial que seja, ele não poderá apreciar ao mesmo tempo o jogo do ballet anárquico das labaredas na lareira e o jogo de bola das crianças no bosque à frente da minha janela.

Mas devemos perseguir esta trilha. Eu insisto na perspectiva de ver constituído discursos coerentes sobre o desporto. Pelo menos alguns discursos que tentem justificar nossa paixão por esta bela obra da humanidade. Não tenho mais a esperança e nem a pretensão de ver desenhado algo do tipo ciências do desporto (tão pouco ciência da motricidade humana ou ciências do movimento humano). Pelo menos de forma epistemologicamente justificada. Aprendi com meu amigo Hugo Lovisolo (1995), que conhecer cientificamente o desporto significaria reduzi-lo a seus elementos simples e processos básicos e, se a análise fosse bem sucedida, teríamos a possibilidade de reconstituí-lo a partir dos elementos simples e dos processos básicos. E, se possível fosse tal realização, poderíamos prever seus mecanismos e como tal estaríamos em condição de, pelo menos em grande parte, evitar o imprevisível, evitar sua configuração aleatória, o que significaria, me atrevo a dizer, acabar com a própria essência ou natureza filosófica do desporto.

Insisto, mas nem por isso devemos defrenestrar o estudo científico das diversas formas de observar o desporto. Gostaria de expressar com muita clareza minhas idéias. Ou seja, o conhecer científico sobre o desporto é de extrema relevância na explicação de seus mecanismos diversos. Todavia, é evidente, o conhecimento científico nos impõe uma visão reducionista do fenômeno e, portanto, não será por esta via que poderemos apreender o desporto em sua complexidade e pluralidade de sentidos. Voltarei a este tema mais à frente.

Mas, por mais paradoxal que possa parecer nosso discurso, podemos afirmar que o conhecimento científico e filosófico sobre o desporto avançou muito nos últimos tempos. E se por um lado, nossa construção teórica seja sempre uma criação da idéia sobre a realidade concreta (cf. Leonardo Coimbra), hoje, mais do que ontem, podemos usufruir de um quadro de conhecimentos que possibilita uma compreensão mais eficaz dos mecanismos, do significado e sentidos do fenômeno desportivo para a humanidade. 
Mas, o que tenho a pretensão de vincar neste ensaio é que esta será uma construção complexa. É uma tarefa de síntese onde a ciência é relevante, mas onde o cientista de qualquer disciplina isoladamente não consegue perceber o todo. Ou seja, o cientista nos limites das fronteiras de sua disciplina perde a noção de complexidade do fenômeno. Não pode ao mesmo tempo desfrutar da estética do bailado do fogo e das crianças a jogar bola. Enfim, no dizer de Lovisolo, a ciência não permite que o cientista do interior de sua disciplina possa exercitar a arte da mediação. Mas o que significa a arte da mediação que nos propõe Lovisolo? Em primeiro lugar significa percebermos que no espaço de intervenção sobre o desporto convivem saberes diversos: conhecimentos teóricos, empíricos, técnicas e artes.

Sobretudo, quando levamos em consideração que a intervenção deve, habitualmente, mediar entre valores de difícil conciliação. Assim, por exemplo, deve conciliar os valores da tradição estética de um desporto com o valor de ganhar a competição1 (...). A intervenção demanda a mediação entre disciplinas díspares. Hoje no treinamento de uma equipe não se pode depreciar a bioquímica aplicada no campo da fisiologia e da nutrição, a fisiologia e a nutrição no desenvolvimento do potencial dos atletas, a psicologia individual e de grupo, a psicologia social e tantos outros conhecimentos. Entretanto, nessa aplicação, sabemos que precisamos do regente da orquestra. O diretor que indica quando entra cada instrumento, o tempo que tocará, a importância que terá o trabalho de conjunto.

(Lovisolo, 1995, p.146)

Se considerarmos correta esta perspectiva, decorrem daí algumas questões cruciais: a quem cabe a arte da mediação no espaço das teorias sobre o desporto? A quem cabe o papel de selecionar os conteúdos relevantes capazes de dar sentido teórico ao fenômeno desporto? Qual o papel das diversas ciências aplicadas ao desporto na construção desse mosaico? Como organizar tudo isso na formação de um desportólogo?

Essas questões me parecem centrais no atual estágio de debates no âmbito da epistemologia do desporto. Isto porque já tentamos torná-la um campo de aplicação do conhecimento científico - as ciências do desporto; já tentamos torná-la uma disciplina científica - a ciência do desporto, no entanto, como sugiro adiante, tais tentativas, do meu ponto de vista, ficaram muito aquém da possibilidade de traduzir em discurso um modelo mais ou menos isomórfico sobre o significado do desporto. Não conseguem, por exemplo, traduzir a síntese de significados que se expressa no jogo de bola das crianças no bosque.

\section{DAS CIÊNCIAS DO DESPORTO A ARTE DA MEDIAÇÃO. UM TRAJETO ENTRE 0 PORTO ALEGRE E O PORTO SENTIDO}

\subsection{A possibilidade das Ciências do Desporto}

O saber científico e filosófico sobre o desporto foi o tema de minha primeira experiência como estudante no Porto Sentido. O objetivo era singelo, mas de certa forma ambicioso e perigoso. Sob a vigilância de Jorge Bento e Adalberto Dias de Carvalho, assistido constantemente pela crítica severa de António Marques, tinha a pretensão de encontrar resposta para a seguinte questão:

Pode o desporto reivindicar um quadro conceitual autônomo construído a partir de um espaço próprio de investigação?

Em outras palavras:

Faz sentido falar-se em ciências do desporto?

Tratei deste tema tendo como material empírico de investigação as produções científicas brasileira e portuguesa. Ao encerrar minha pesquisa a conclusão foi evidente:

Considerando o conjunto de fatores que se expressam no âmbito das ciências do desporto, pode-se concluir que, ao configurar-se como focagem múltipla sobre um objeto comum feito no isolamento disciplinar a partir de diferentes perspectivas de análise e reflexão, tais formas de conhecimento não permitem a demarcação de um espaço de saber para o desporto capaz de expressar toda sua dimensão. Nas ciências do desporto não há a possibilidade de se constituir uma perspectiva que implique em ruptura com a estrita dependência relativa às disciplinas científicas de origem “(...) mesmo que estas disciplinas lhes prestem serviços relevantes ou pretendam colar-se a ela acrescentando, à sua designação original e normal o adjetivo desportivo". (Gaya, 1994, p.127) 
Evidentemente que no bojo de tal síntese estava declarado de forma explícita a impossibilidade, pelo menos de forma epistemologicamente justificada e considerando o amplo espectro de objetivos expressos na produção científica, de constituição de um campo científico específico sob a denominação de ciências do desporto 2 .

As causas desta conclusão eram devidas principalmente a um conjunto de fatores tais como:

a) as investigações respondem predominantemente às questões advindas das disciplinas de origem;

b) a própria delimitação das variáveis independentes de investigação, embora referenciadas ao desporto, encontram-se distanciadas das necessidades intrínsecas das práticas desportivas;

c) os conhecimentos são parcializados, fragmentados e desarticulados.

Nas ciências do desporto construímos conhecimentos objetivos sobre a biologia, fisiologia, biomecânica, antropologia, sociologia, psicologia. Construímos discursos sobre pedagogias e a arte de ensinar. Aplicamos esses conhecimentos a desporto de crianças e jovens, ao desporto de rendimento, ao desporto para portadores de necessidades especiais, ao desporto de lazer. Mas seja a ênfase que se dê a estes campos do conhecimento, temos de reconhecer que cada um desses cientistas operam no quadro teórico de suas disciplinas específicas e essas disciplinas se configuram como compartimentos isolados ou com pequeno grau de comunicação. Enfim, nas ciências do desporto, não se configura a possibilidade da arte da mediação.

\subsection{A expectativa de uma Ciência do Desporto}

Todavia, em outra oportunidade, cheguei a ensaiar a possibilidade de ver constituída a ciência do desporto (já agora no singular) considerando o campo de estudo do treino desportivo (Gaya, 1994b). Considerando, evidentemente, a exigência da delimitação de um objeto teórico formal e de metodologias adequadas. A partir do pressuposto de que o objeto de estudo de uma determinada disciplina é constituído pelo conjunto conceitual construído com o fim de se dar conta de uma multiplicidade de objetos reais que, por hipótese, essa ciência tem em vista analisar (cf. Castells, sd). Elegi como provável objeto teórico formal para a ciência do desporto a capacidade de prestação desportiva. Definindo-a como um processo multiforme de utilização racional de fatores combinados mutuamente de modo a exercer influência sobre o desempenho do desportista e assegurar seu nível de prontidão. E mais, referi que esses fatores se constituíam de:

a) formas motoras, habilidades motoras de base, técnicas desportivas, condição física, tática e volitiva;

b) os procedimentos metodológicos para o desenvolvimento das capacidades motoras e condicionais;

c) a organização e planejamento do ensino e do treino de habilidades desportivas;

d) as condições psico-sociais;

e) o desenvolvimento e aperfeiçoamento de meios complexos de análise, prognose e controle da prestação desportiva para cada especialidade;

f) critérios normativos a valorizar na prospecção de talentos desportivos.

Prontamente, na edição seguinte da Revista Horizonte, recebi severas críticas de Jorge Bento (Bento 1994) e, lembro-me ainda hoje, quando de minha argüição de doutoramento que Jorge Bento com o brilho que lhe é peculiar e com a exigência estética e que impõe a sua retórica, vigorosamente não concebia a Pedagogia do Desporto como conteúdo de uma ciência do desporto cujo o carro chefe seria o Treino Desportivo.

Por algum tempo não me deixei impressionar pelas críticas de meu professor e querido amigo. A situava mais no âmbito de um carinhoso "corporativismo pedagógico" do que propriamente pela força de seus argumentos. Lembro ainda que na réplica referi que a pedagogia na perspectiva de tornar-se uma filosofia, ou em outras palavras, na procura de tornar-se transcendente e acima do mundo concreto afastara-se das quadras, piscinas, pistas, ginásios, academias e insistia em idealismos, muito dos quais transferidos de outras ciências sociais e apressadamente adaptados ao campo dos discursos sobre o desporto, não traduziam o mundo real das práticas desportivas. 
Referi ainda que em alguns casos mais extremos, evidentemente onde não se inclui Jorge Bento, essa pedagogia negava a própria essência biológica do homem. Todavia, não falei, embora vontade não me faltasse (mas a prudência exigia), que o desporto para muitos desses pedagogos e uns tantos filósofos parecia constituir-se numa prática para anjos, querubins e outras santidades.

Não obstante, nesta perspectiva de uma ciência do desporto tendo como referência o treino desportivo, embora fosse mais evidente a possibilidade de cercarmos nosso objeto de estudo de forma a constituirmos uma disciplina científica, o projeto é ainda mais reducionista que o das ciências do desporto. Assim se, nas ciências do desporto temos uma área de conhecimento, que embora não seja capaz de expressar a síntese entre o significado plural do desporto, pelo menos possibilita a pluralidade de interpretações através das diversas disciplinas científicas que a compõe. Na ciência do desporto esta possibilidade é claramente impossibilitada. Na ciência do desporto perdemos qualquer possibilidade de efetivar a arte da mediação.

Enfim, das ciências do desporto a ciência do desporto foi um caminho que trilhei por longo tempo. Mas, hoje reconheço, é uma perspectiva limitada no sentido de perceber a complexidade inerente ao sentido complexo do desporto em nossa sociedade. Mas se por outro lado, considerarmos a perspectiva proposta por Lovisolo sobre a arte da mediação como efetivá-la? E, qual seria o papel das instituições universitárias?

\section{A UNIVERSIDADE DO PORTO E SEU PAPEL NA PRODUÇÃO DO CONHECIMENTO E MEDIAÇÕES POSSÍVEIS SOBRE O DESPORTO NO ESPAÇO DA LÍNGUA PORTUGUESA.}

O que proponho neste ensaio é uma breve reflexão sobre o papel que tem exercido, principalmente para os países de língua portuguesa, a produção do conhecimento da FCDEF-UP e, se esta produção já permite alguma mediação capaz de configurar sínteses sobre o significado do desporto? Pois reafirmo, sem medo de cometer equívoco, a FCDEF-UP, em ações com importantes Universidades brasileiras e com a Universidade Pedagógica Maputo, a partir do amplo espectro de publicações, cursos, mobilidade de professores e estudantes, em programas de doutoramento, tem proporcionado conteúdo teórico e empírico capaz de permitir a arte da mediação. Feito no quadro multidisciplinar de seus gabinetes, ou num quadro de intervenção no espaço do pensamento filosófico sobre o desporto podemos apontar o esboço de concepções teóricas que tem influenciado de forma relevante o pensamento sobre o desporto no espaço da cultura lusófono.

\section{Conceito de desporto plural}

Um dos principais conceitos que perpassam as diversas publicações no âmbito dos estudos sobre o desporto no espaço da cultura portuguesa é o de desporto plural expresso nas obras de Jorge Bento. Aí se evidencia a compreensão de que o desporto propicia diversas intencionalidades que diferem a partir dos objetivos, dos sentidos e das necessidades de seus praticantes. O desporto de excelência, o desporto de crianças e jovens, o desporto de reabilitação e reeducação, o desporto de lazer. Embora muitas vezes este conceito seja entendido de forma pouco adequada, mesmo assim tornou-se uma referência para diversos trabalhos publicados no espaço da cultura lusófona.

O conceito de desporto plural permitiu a quebra da hegemonia do significado único do desporto como prática restrita a sua expressão de alto rendimento. Permitiu a relativização do conceito e com isso uma compreensão mais adequada de seu significado. Hoje, é evidente que encontramos muitas referências ao conceito de desporto plural. Em publicações, em linhas de pesquisa de cursos de pós-graduação estricto senso, em cursos de pós-graduação lato senso, em disciplinas de formação acadêmica, congressos encontramos seguidamente as denominações relacionadas a expressões específicas como esporte de rendimento, esporte de lazer, esporte de crianças e jovens e desporto de reabilitação. Sem dúvida o conceito de desporto escolar é um conceito que já faz parte do quadro teórico dos países de expressão portuguesa.

\section{Para uma teoria do treino dos jovens desportista}

O sistema de treino e de competições dos mais jovens sempre expressou uma preocupação central nas 
investigações de António Marques. É central em seus textos publicados ou em seu material didático de aulas e em suas conferências e palestras a preocupação com uma estrutura coerente que respeite a formação integral de crianças e jovens desportistas. Destes textos de Marques pelo menos duas preocupações emergem em forma de um pensamento bem configurado. A estruturação dos programas de treino e a organização do quadro competitivo. Descritas, em diversos ensaios, de forma muito coerente e relacionadas estas teorizações tem se constituído numa referência a um conjunto numeroso de dissertações de mestrado e algumas teses de doutorado nos países de língua portuguesa.

Os estudos de Marques, que consideram a formação do jovem desportista em dois períodos subdivididos em duas etapas: Período de treino de base que abrange a etapa de preparação específica e especialização inicial; período de realização das aptidões e capacidades desportivas que abrange a etapa de especialização aprofundada e a etapa de rendimentos elevados, apresentam aspectos que atendem as preocupações de ordem pedagógica que satisfazem as exigências da formação integral da criança e do jovem. As preocupações inerentes a equalização do treino com as tarefas escolares e demais necessidades inerentes ao cotidiano dos mais jovens representa um quadro de referência diferenciado que tem consubstanciado um valor inegável ao pensamento do autor.

É, do meu ponto de vista, evidente que as teorizações de Marques sobre os programas de treino e competições para os mais jovens se consubstanciam numa referência teórica importante para a investigação em ciências do desporto no espaço lusófono.

\section{Ensino dos jogos desportivos coletivos}

A partir da publicação do livro O Ensino dos Jogos Desportivos, editados por Amândio Graça e José Oliveira e com a participação do conjunto de professores que constituem o Centro de Estudos dos Jogos Desportivos da FCDEF-UP, o espaço da língua portuguesa ganha uma obra de referência do campo da pedagogia do desporto. Partindo de três estudos de fundamentação teórica: Para uma Teoria do Jogos Desportivos de Júlio Graganta; Os Comos e os
Quandos no Ensino dos Jogos de Amândio Graça e O Processamento da Informação nos Jogos Desportivos de Fernando Tavares, o estudo apresenta um conjunto de propostas metodológicas advindas dos diversos gabinetes da FCDEF-UP. O ensino do andebol; do basquetebol; do futebol; do voleibol e, na segunda edição do livro, complementados pelo ensino do waterpolo e do rugby.

Sendo essa uma das minhas áreas de atuação no âmbito do ensino de graduação e pós-graduação no Brasil, sinto-me muito a vontade para dar testemunho da importante influência deste estudo no plano dos estudos pedagógicos. Mesmo sem estar publicado no Brasil, o que limita seu acesso a grande massa de professores de educação física, a produção de dissertações e teses, de artigos científicos, palestras e cursos revelam a presença frequente desta obra como referência bibliográfica relevante.

\section{Meio Ambiente e o Desporto}

O Meio Ambiente e o Desporto é obra editada pelo brasileiro Lamartine Pereira da Costa e organizado pelo português António Teixeira Marques. É oriunda de um seminário realizado na FCDEF-UP. Publicada em 1997, com a participação de vários professores dos países europeus e das américas. Este livro, escrito em português e inglês, tem exercido influência para além das fronteiras dos países de língua portuguesa, e tem se constituído em documento de reflexão para a comunidade do desporto sobre as relações entre desporto e meio ambiente. Contendo conteúdos tais como: Por uma Teoria do Meio Ambiente; Desporto e Natureza: Tendências Globais e Novos Significados; Várias Formas do Pensamento Ambientalista no Campo das Atividades Desportivas; Desporto Natureza e Sociedade; O Corpo Contemporâneo em Crise Ecológica; O Conflito entre Desporto e Conservação do Ambiente; A Ética Ambiental e o Comitê Olímpico Internacional, entre outros, esta obra disponibiliza subsídio de muita relevância para o debate de um tema contemporâneo do maior significado.

\section{Sobre a Seleção de Jovens Desportistas}

A seleção de jovens desportistas para as praticas desportivas mais exigentes tem sido motivo de muitos debates na literatura internacional. Com 
muitas hipóteses e poucas certezas o tema é dependente de tecnologias e metodologias adequadas para seu desenvolvimento. Pois também nesta área a FCDEF-UP tem prestado efetiva colaboração internacional através de investigações no âmbito dos métodos quantitativos de José Maia. Os modelos de análise de estrutura do tipo simplex quasi-markoviano, um modelo auto-regressivo que utiliza variáveis latentes compostas por múltiplos indicadores de performance com erro de medida, se revela como ferramenta essencial para uma proposta metodológica sobre a estabilidade da aptidão física.

Além desse aspecto específico, José Maia com sua indiscutível competência no que se define como área dos métodos quantitativos tem se constituído numa referência para pesquisadores, principalmente do Brasil, Moçambique e Cabo Verde. Já são muitos os grupos de pesquisa nesses países que dedicados a área da promoção da saúde, da modelação da performance desportiva e de estudos epidemiológicos, encontram referência nos trabalhos e orientações deste pesquisador português.

Certamente nesta breve revisão escapam tantas outras possibilidades efetivas de produção do conhecimento que a FCDEF-UP e seus aliados tem proporcionado como subsídios para a arte da mediação no espaço da cultura portuguêsa. Referências para a compreensão do desporto escolar são evidentes nos estudos de Amândio Graça e do Gabinete de Pedagogia do Desporto. O mesmo deve ser afirmado em relação ao desporto de lazer conduzido por Jorge Mota; do desporto adaptado pelo Gabinete de Educação Física Especial; da biologia do desporto pelo respectivo gabinete.

Enfim, muito se tem feito em torno da FCDEF-UP com a colaboração de estudantes, professores, pesquisadores dos demais países de língua portuguesa que, através de convênios, protocolos de cooperação, publicação de livros, congressos, seminários, aulas, mobilidade de alunos e professores tem construído, com cimento agregador, a comunidade do desporto nos países lusófanos.

Evidentemente há muita mediação para ser exercitada. De nossas limitações biológicas (que não nos permite ver em simultâneo o ballet das labaredas e o jogo de bola das crianças no bosque), produzimos estudos parciais. Mas é inequívoco que já há material de boa qualidade que a FCDEFUP e seus colegas produziram, ou que encontram algumas sínteses de relevância teórica no quadro de teorias sobre o desporto.

Avançar neste caminho é um compromisso de todos nós que labutamos no espaço da cultura lusófona. Que bom seria se pudéssemos percorrer este caminho sem divisões, sem erguermos barreiras e preconceitos entre áreas, entre formas de escolher o método de investigação. Mas também se torna relevante considerar que deveremos desenvolver um quadro de estudiosos e pesquisadores que rompendo com as barreiras das fronteiras disciplinares, possam exercer com liberdade a arte da mediação. Talvez seja nossa tarefa para a próxima década. 


\section{NOTAS}

${ }^{1}$ Não poderíamos explicar o auge internacional do basquetebol pelo fato dos norte-americanos haverem conciliado valores estéticos do esporte com a alta competitividade? (Lovisolo, 1995, p.146)

${ }^{2}$ Nesta mesma perspectiva considero a impossibilidade da ciência da motricidade humana, ciência do movimento humano ou ciência da educação física.

\section{REFERÊNCIAS BIBLIOGRÁFICAS}

Bento, J.O. (1994) Sobre o Estado da Ciência do Desporto. Horizonte, vol.XI, No 63- Novembro.

Castell, S. M. \& Ipola,E. (s.d.) Prática Epistemológica em Ciências Sociais. Porto, Afrontamento.

Gaya, A.C.A. (1994). As Ciências do Desporto nos Países de Língua Portuguesa. Uma abordagem epistemológica. Porto, Universidade do Porto.

Gaya, A.C.A. (1994). Das ciências do Desporto à Ciência do Desporto. Notas Introdutórias para uma Epistemologia da Ciência do Desporto. Horizonte, Vol XI, No 63- Setembro. Lovisolo, H. (1995) Educação Física. A Arte da Mediação. Rio de Janeiro, Sprint. 